\title{
A CONTRIBUIÇÃO PROFISSIONAL E QUALIFICADA DO ASSISTENTE SOCIAL NO PROGRAMA BOLSA FAMÍLIA
}

\section{THE CONTRIBUTION OF SKILLED AND PROFESSIONAL SOCIAL WORKER FAMILY SCHOLARSHIP PROGRAM}

\section{Mireille Alves Gazotto ${ }^{1}$}

Resumo: Este artigo denominado "A contribuição profissional e qualificada do assistente social no Programa Bolsa Família" tem como objeto de estudos as famílias beneficiadas por este programa do Governo Federal no município de Pirajuba-MG. O enfoque é demonstrar o trabalho qualificado do profissional assistente social junto as famílias beneficiadas pelo Programa Bolsa Família-PBF através de visitas domiciliares realizadas pelo assistente social com o objetivo de veicular informações dos direitos de acesso e das condicionalidades para permanência no Programa Bolsa Família. Com fundamentação nesses objetivos busca-se analisar no campo das relações sociais concretas e históricas da família com análise crítica da realidade e, concomitante com esta realidade, o trabalho do assistente social. Para fundamentação deste estudo utiliza-se a revisão literária para maior clareza; o Guia do Gestor, o Manual de Gestão de Condicionalidades do Programa Bolsa Família e as leis e diretrizes que instituem este programa do Governo Federal. Desta forma, este artigo vem contribuir para uma análise crítica da realidade do município de Pirajuba-MG perante o Programa Bolsa Família e a contribuição qualificada do trabalho do(a) assistente social no cotidiano das relações sociais referente a esta demanda.

Palavras-chave: Programa Bolsa Família. Usuários. Assistente social.

\begin{abstract}
This article entitled "The contribution of professional and qualified social worker in the Family Grant Program" has as its object of study of the families benefited by this Federal Government program in the municipality of Pirajuba-MG. The focus is to demonstrate the work of professional qualified social worker with the families supported by GMP-Family Grant Program through home visits by social workers in order to convey information access rights and conditionalities to stay in the Family Grant Program. Reasoning with these objectives we seek to analyze the field of concrete social relations and family history with a critical analysis of reality, and concomitant with this reality, the work of social workers. For reasons of this study we use the literature review for clarity, the Manager's Guide, the Manual on Management of Conditionalities's Bolsa Familia Program and the laws and guidelines establishing this federal program. Therefore, this article contributes to a critical analysis of the reality of the city of Pirajuba-MG to the Family Grant Program and the contribution of skilled labor social worker in everyday social relations for this demand.
\end{abstract}

Keywords: Bolsa Familia. Users. Social worker.

\footnotetext{
${ }^{1}$ Assistente social na Universidade Federal do Triângulo Mlneiro lotada no Núcleo de Assistência Estudantil-NAE. Especialista em Docência do Ensino Superior pela FIJ-RJ. E-mail: mireille@servicosocial.uftm.edu.br
} 


\section{INTRODUÇÃO}

As desigualdades sociais geradas pelo sistema capitalista de produção e reprodução das relações sociais entre as classes - que detêm o poder e os que necessitam vender a sua força de trabalho para viver - produz e reproduz um contingente de famílias desprotegidas, pois na conjuntura econômica atual vivenciase a flexibilidade no emprego, para a redução do quadro de funcionários e aumento dos serviços terceirizados, aumento de desempregados que não possuem uma educação e/ou qualificação adequada para investidura de cargos que antes necessitavam de uma escolarização de nível baixo em que na atualidade já se eleva os pontos de classificação educacional para adequar-se ao emprego almejado.

Assim, no âmbito familiar, concomitante ao processo de produção e reprodução do capital, realiza-se de forma determinada e determinante o processo histórico de produção e reprodução da pobreza dessas famílias e, com ela, agravam-se as condições de vida - saúde precária, alimentação insuficiente ou nula - fome; condições de moradia inabitáveis sem infra-estrutura básica; êxodo escolar das crianças para trabalhar e ajudar na renda doméstica - exploração do trabalho infantil; violências - exploração sexual; aumento de dependentes químicos; dificuldades na acessibilidade a projetos, programas, instituições, unidades básicas de saúde, etc.. Ou seja, a exclusão social.

Hoje a noção de exclusão se forma nas mais diferentes sociedades resultantes do processo econômico e das transformações do mundo do trabalho. A nova noção de exclusão aparece na década de 1990 no debate intelectual e político. Foi René Lenoir que inventou a noção em 1974. Ele debateu em torno da concepção de exclusão como um fenômeno de ordem social e não individual que deveria ser buscado na funcionalidade das sociedades modernas e que não se tratava de um fenômeno marginal atribuído à classe subproletariada, mas de um processo em curso atingindo todas as camadas sociais.

Dependendo do espaço que essa exclusão se refere ela terá uma contextualização diferente. Nos países de primeiro mundo ela aparece com um novo conceito: de nova pobreza, pois os trabalhadores desempregados por um longo tempo não conseguem emprego mesmo sendo considerados aptos ao trabalho e adaptado à sociedade moderna sendo vítimas de todo um conjunto da crise econômica. No Brasil existem diferentes causas de exclusão social e pobreza sendo 
que elas estão marcadas pela historicidade do país mostrando uma discriminação econômica, cultural e política além de étnica.

Assim, pobreza e exclusão não são iguais, mas estão sempre articuladas. A pobreza leva a ruptura de vínculos sociais representando precariedades não significando necessariamente exclusão. Mas a pobreza atualmente está ligada a outros fatores como difícil inserção no mercado de trabalho, o precário acesso aos serviços públicos e, especialmente, a ausência de poder tornando esses fatores como novo conceito de pobreza associado ao de exclusão sendo tomada pela sociedade na contemporaneidade como nova manifestação da questão social.

No Brasil devido as suas particularidades no seu contexto cultural, político econômico e social a exclusão está sempre camuflada na sociedade ao demonstrar no cotidiano personagens que são incômodos politicamente, ameaçadores socialmente e desnecessários economicamente.

Desta forma, há ausência de oferta que ofereçam condições dignas para as famílias saírem do campo da vulnerabilidade social/da desproteção social, cultural e financeira para que estas possam ir para o campo da proteção sendo um dos meios para o enfrentamento da pobreza, da fome e da exclusão social com redução das desigualdades sociais e da proteção social que está fundamentada desde a promulgação da Constituição Federal de 1988, a "Constituição Cidadã".

Essas responsabilidades demonstradas nesta introdução pertencem e articulam com as três esferas de governo: Federal, estadual e municipal, que para nosso interesse, através do Conselho Gestor do Programa Bolsa Família (PBF). Essas três esferas possuem competência para oferecer apoio às famílias, combater as desigualdades, enfrentar as causas da pobreza, promover a inclusão social, integração e sua equidade.

As responsabilidades de repasses orçamentários, de obrigações e funções referentes ao Programa Bolsa Família (PBF) iniciam-se na esfera do Governo Federal pelos ministérios do Desenvolvimento Social e Combate à Fome, Educação, Saúde, Fazenda, Planejamento e Casa Civil, e pelo presidente da Caixa Econômica Federal. Destes, de forma descentralizada e participativa, são repassados para os estados e deste, é repassado para os municípios a coordenação e o apoio para a implementação do Programa. Assim conclui-se que, é na esfera municipal que o PBF concretiza suas ações junto aos usuários. 


\section{O TRABALHO QUALIFICADO DO(A) ASSISTENTE SOCIAL NO PROGRAMA BOLSA FAMÍLIA DE PIRAJUBA-MG}

Para compreender o trabalho do(a) assistente social em programas oferecidos pelo Governo Federal deve buscar uma perspectiva crescente no campo dos direitos sociais onde, o assistente social, com capacidade teórico-metodológico, técnico-operativo e ético-político realiza seus processos de trabalho contribuindo para a emancipação dos sujeitos que participam do Programa Bolsa Família.

A realização desse trabalho relacionado ao fazer profissional do assistente social possibilita uma aproximação da realidade vivenciada pelos usuários do Programa Bolsa Família através de visitas domiciliares. Para isso, utilizou-se o Guia do Gestor e o Manual de Gestão de Condicionalidades do Programa Bolsa Família desenvolvido pela Secretaria Nacional de Renda e Cidadania - Ministério de Desenvolvimento e Combate à fome - exemplificando e fundamentando as leis e diretrizes que instituíram o Programa Bolsa Família tornando objetiva as informações essenciais referente à gestão do Programa e de suas condicionalidades.

Outra base de apoio que se teve acesso foi referente a ficha socioeconômica e o Caderno da Família que estão cadastradas no CRAS - Centro de Referência em Assistência Social - possibilitando a formação de indicadores referentes ao Programa Bolsa Família.

O principal objetivo alcançado do trabalho com essa metodologia foi 0 aprendizado do tema estudado com significativa relação entre teórica e prática. Para que isso ocorresse foi fundamental a busca por respostas às questões cuja origem estava nas pessoas beneficiadas pelo Programa e a contribuição de outros profissionais.

A partir destas informações sabe-se que, o município de Pirajuba-MG possui de acordo os dados do IBGE, estimativa 2007, 3.694 habitantes. Deste total de habitantes há uma estimativa de inserção no Cadúnico de 295 famílias e que, destas famílias, existem a probabilidade de 166 famílias com perfil para receber Bolsa Família. Desta forma, com a análise dos cadastros, o município de PirajubaMG, em outubro de 2008, havia apenas 83 famílias liberadas para receberem o benefício Bolsa Família do Governo Federal, pois não havia uma sistematização de ações profissionais voltadas para a publicizar o processo de entrada das famílias com perfil para participarem deste Programa do Governo Federal. 
Desta gama populacional existem famílias que (sobre)vivem em condições de vulnerabilidade social sofrendo vários tipos de desproteções, uma vez que, mesmo sendo constatado no atual governo municipal um desenvolvimento a favor de melhores condições de vida através da moradia própria; das oportunidades de emprego com a vinda de empregadores e empresas; da melhoria da saúde, da educação e da cultura há muitas famílias que, por causa de seu processo histórico de (re) produção da sua pobreza e do seu modo de sobreviver, não conseguem sobressair sozinha desse "círculo vicioso" que encontra seu contexto familiar.

Quando se fala em família deve-se considerar a sua história retratando o seu processo de formação

Nos termos de Gueiros (2002) até o século X a família, inclusive em termos de patrimônio ganha força apenas em aspectos de linhagem com o objetivo da não divisão do patrimônio. Ou seja, para continuar o poder que se fundamentava no acúmulo de terras, as famílias constituíam casamentos entre parentes próximos: os mais comuns eram entre primos e primas de primeiro grau; e entre tios e sobrinhas.

No século XIV, começam mudanças na família medieval. A mulher começa a ter perdas nos seus poderes obtendo a formalização da incapacidade jurídica da mulher e o pleno poder do homem na família, mostrando desta forma a desigualdade entre o homem e a mulher onde, neste momento, fortalecia a família patriarcal tendo o homem plenos poderes sobre a mulher.

No século XVIII, dá-se a separação entre família e sociedade, dando importância à intimidade, ou seja, neste período a sociedade impõe a privacidade entre as pessoas da própria família: separando cômodos na arquitetura das casas. Isso foi uma das maiores mudanças na vida cotidiana das famílias em que a igualdade entre os filhos é vista como civilidade. Neste momento esse fator se deve ao processo histórico referente à Revolução Industrial e, concomitante, à Política liberal $^{2}$.

Importante observar que essas mudanças nas famílias de um período para outro só se faziam em famílias que tinham melhores condições de vida, ou seja, as mais abastadas ficando as famílias "pobres" a mercê dos mandos da classe burguesa e vivendo de forma desumana.

\footnotetext{
${ }^{2}$ A política liberal, no século XIII-XVIII, visa na busca individual de se sobressair ao sistema capitalista em que todas as responsabilidades são voltadas a capacidade individual de cada um. Já o neoliberalismo, século XIX aos dias atuais, visa Estado mínimo em que o mercado "cuida" dos que detem o poder de compra e, o Estado "cuida" dos que estão a margem do sistema capitalista.
} 
Mas com o movimento feminista e o processo de modernização no século XIX a estrutura de família passa a ser questionado desenvolvendo um modelo da família conjugal moderna.

Desta forma, com o processo de modernização em que a educação, o trabalho, os movimentos sociais, as diferenças nas classes sociais ganharam de certa forma novos aspectos tanto negativos como positivos. Isso gerou mudanças no seio da família, onde na segunda metade do século XX é que se pode obter em termos jurídicos a emancipação da mulher a qual se constituiu como cidadã e como sujeito. O casamento se tornou uma escolha mútua com critérios afetivos, sexuais e uma noção de amor com a importância do indivíduo em sua privacidade.

Houve também nessa modernização de família novos arranjos familiares como: famílias monoparentais que no caso, da maioria, são chefiadas por mulheres. Outros fatos significativos observado na família moderna são o elevado crescimento do divórcio, a diminuição do casamento civil e religioso, a diminuição de filhos, etc.

Do ponto de vista da evolução da família e da observação da prática profissional se vê a diferenciação de se organizar entre as famílias de classe baixa e de classe média em que seus "modelos" de família são considerados de maneiras diferentes.

De acordo com essa base teórica é muito importante para a prática profissional do assistente social, e outras áreas profissionais afins, saber o processo histórico de formação da família e sua caracterização perante as ideologias geradas pelo classe burguesa no processo de produção/reprodução do sistema capitalista para que, na esfera pública, o assistente social, possa trabalhar no campo do direito implementando políticas sociais públicas de caráter universalista para assegurar a proteção e emancipação social dos sujeitos sociais.

Com isso, o Programa Bolsa Família vem oportunizar que as famílias pertencentes ao município de Pirajuba-MG e tantas outras que são transferidas para o município de Pirajuba-MG através da imigração de trabalhadores e de suas respectivas famílias flutuantes - como consta nesta realidade cotidiana - trabalhador no corte de cana - possam sair da condição de vulnerabilidade social, podendo tornar-se pessoas com a garantia de seus acesso a bens e serviços, e dando oportunidade para a inserção de outros beneficiários no Programa.

É bem lembrado que, este Programa gera um benefício para suprir as necessidades imediatas aliviando a pobreza, oferecendo acessibilidade na saúde e 
na educação e, como fator último, acesso aos Programas complementares que podem estar nas três esferas governamentais e na sociedade civil. Tem-se como exemplo o PAIF (Programa de Atenção Integral à Família), Geração de Renda, Alfabetização de Jovens e Adultos e outros.

Para fundamentar o exposto, segue art. $2^{\circ}$ do Decreto 5.209, de 17 de setembro de 2004, que cria o Programa Bolsa Família, cabendo ao Ministério do Desenvolvimento Social e Combate à Fome - MDS a coordenação, a gestão e a operacionalização do Programa Bolsa Família, que compreende a prática dos atos necessários à concessão e ao pagamento de benefícios, a gestão do Cadastramento Único do Governo Federal, a supervisão do cumprimento das condicionalidades e da oferta dos programas complementares, em articulação com os Ministérios setoriais e demais entes federados, e o acompanhamento e a fiscalização de sua execução. Com isso, segue abaixo as responsabilidades e competências do ente federado municipal:

- Identificação e inscrição no Cadúnico das famílias em situação de pobreza e extrema pobreza;

- $\quad$ Gestão dos benefícios do PBF e Programas Remanescentes; cabíveis;

Apuração e/ou o encaminhamento de denúncias às instâncias

- $\quad$ Garantia do acesso dos beneficiários do PBF aos serviços de educação e saúde, em articulação com os Governos Federal e Estadual;

- $\quad$ Acompanhamento do cumprimento das condicionalidades na área da assistência social, da educação e da saúde;

- Acompanhamento das famílias beneficiárias, em especial atuando nos casos de maior vulnerabilidade social;

- $\quad$ Estabelecimento de parcerias com órgãos e instituições municipais, estaduais e federais, governamentais e nãogovernamentais, para a oferta de programas complementares aos beneficiários do Programa Bolsa Família.

- $\quad$ Atualização das informações do Cadastro Único (Cadúnico), apuradas por meio do percentual de cadastros válidos e do percentual de domicílios atualizados nos últimos dois anos;

Desta forma, para que efetive as responsabilidades e competências em âmbito municipal foram acompanhadas por uma profissional assistente social no ano de 2008, através de visitas domiciliares, as famílias cadastradas no Cadúnico com o "benefício" Bolsa Família liberado e as famílias com o "benefício" cancelado com a finalidade de regularizar a sua situação e inserir novas famílias com perfil para receber o benefício. 
Para a efetivação destas propostas foi necessário a requisição do profissional assistente social pela Prefeitura Municipal de Pirajuba-MG juntamente com o CRAS através de verba do IGD (Índice de Gestão Descentralizada do Programa Bolsa Família) publicado na Portaria no 148, de 27 de abril de 2006. Seus recursos que são recebidos por intermédio do IGD podem ser utilizados para realizar as seguintes atividades de gestão, acompanhamento, cadastramento, implementação de programas complementares e fiscalização. Ou seja, podem sem utilizados através das atividades relacionadas abaixo:

- Gestão de condicionalidades;

- Gestão de benefícios;

- Acompanhamento das famílias beneficiárias, em especial daquelas em situação de maior vulnerabilidade social;

- Cadastramento de novas famílias, atualização e revisão dos dados contidos no Cadastro Único;

- Implementação de programas complementares, nas áreas de: alfabetização e educação de jovens e adultos, capacitação profissional, geração de trabalho e renda, acesso ao microcrédito produtivo orientado, e desenvolvimento comunitário e territorial, entre outras;

- Atividades relacionadas às demandas de fiscalização do PBF e do Cadastro Único, formuladas pelo MDS.

Reconhecendo a realidade social da população beneficiada pelo Programa Bolsa Família e das condições que desfavorecem a realização efetiva e eficiente das ações desenvolvidas no CRAS - quadro enxuto de funcionários; o profissional assistente social, fundamentado na Lei que rege a sua formação e profissão - Lei no 8662/93 respaldado juridicamente pelo seu Conselho Regional de Serviço Social CRESS, pelo Código de Ética Profissional do(a) assistente social de 1993 e com um Projeto de Formação Ético-Político do Serviço Social possui capacidade teóricometodológico, prático-operativo e ético-político para trabalhar de forma efetiva no Programa Bolsa Família. Para isso respalda-se, como foi salientado acima com fundamentação jurídica nas linhas que se seguem de acordo com a Lei nํㅜ 8.662/93 Lei de Regulamentação da Profissão dando ênfase referente a esse Projeto de interveção nos incisos I, II, IV e XII:

Art. $5^{\circ}$ - Constituem atribuições privativas do(a) assistente social:

I - coordenar, elaborar, executar, supervisionar e avaliar estudos, pesquisas, planos, programas e projetos na área de Serviço Social;

II - planejar, organizar e administrar programas e projetos em Unidade de Serviço Social;

III - assessoria e consultoria a órgãos da administração pública direta e 
indireta, empresas privadas e outras entidades, em matéria de Serviço Social;

IV - realizar vistorias, perícias técnicas, laudos periciais, informações e pareceres sobre a matéria de Serviço Social;

V - assumir, no magistério de Serviço Social tanto a nível de graduação como pós-graduação, disciplinas e funções que exijam conhecimentos próprios e adquiridos em curso de formação regular;

VI - treinamento, avaliação e supervisão direta de estagiários de Serviço Social;

VII - dirigir e coordenar Unidades de Ensino e Cursos de Serviço Social, de graduação e pós-graduação;

VIII - dirigir e coordenar associações, núcleos, centros de estudo e de pesquisa em Serviço Social;

IX - elaborar provas, presidir e compor bancas de exames e comissões julgadoras de concursos ou outras formas de seleção para Assistentes Sociais, ou onde sejam aferidos conhecimentos inerentes ao Serviço Social.

$X$ - coordenar seminários, encontros, congressos e eventos assemelhados sobre assuntos de Serviço Social;

XI - fiscalizar o exercício profissional através dos Conselhos Federal e Regionais;

XII - dirigir serviços técnicos de Serviço Social em entidades públicas ou privadas;

XIII - ocupar cargos e funções de direção e fiscalização da gestão financeira em órgãos e entidades representativas da categoria profissional.

Assim, foi efetivado o trabalho junto as famílias do Programa Bolsa Família em que as famílias liberadas para recebimento foram visitadas em seus respectivos domicílios. Na maioria desses domicílios foi observado que essas famílias fazem jus ao recebimento do mesmo. A mãe/responsável consegue criar várias formas de educar seus respectivos filhos com os valores recebidos do governo, tais como: calçados para que seus filhos possam freqüentar a escola sem serem estigmatizados por outros alunos; uma alimentação um pouco diferenciada do dia-adia: carne, verdura, legumes; material escolar; e outros fatores relacionadas à educação.

Nessas visitas foram veiculadas informações, de maneira verbal, quanto ao cadastramento no Cadúnico e no Programa Bolsa Família através de panfletos confeccionado no CRAS e recebidos do Governo Federal, que especificavam os critérios de elegibilidade; os valores recebidos; documentos para cadastramento; o cumprimento das condicionalidades no campo da saúde, da educação e da assistência social não apenas como cumprimento das mesmas para receber o benefício, mas, também, para que possam sair da condição de extrema pobreza e 
de pobreza acessando a rede existente no município: saúde, educação e assistência social.

Quanto a assistência social, relacionada ao Programa Bolsa Família, trabalhase também com os motivos que levaram a morosidade de seus cadastros e recebimentos do benefício Bolsa Família conduzindo-os à técnica de informática do Bolsa Família para terem conhecimento do andamento de seus cadastros ou para realizar novos cadastros das famílias que se enquadram nos critérios de elegibilidade deste Programa. Neste processo de trabalho foi veiculado para as famílias visitadas informações no campo da melhoria da qualidade de vida ao usufruir desse benefício para que, no futuro, possam caminhar com dignidade e respeito sem precisar da "ajuda" do Governo Federal.

De acordo com todo o processo demonstrado acima concluímos o nosso trabalho com a contribuição do(a) assistente social no PBF com 82 famílias contemplando o Programa Bolsa família, através de visitas domiciliares para identificação, atualização, regularização (bloqueio, desbloqueio, cancelamento e cadastro) e orientação sobre o PBF.

\section{CONSIDERAÇÕES FINAIS}

Todo o projeto teve como pressuposto básico a mudança de atitude, requerendo um processo educacional em que a educação continuada, o trabalho com visitas domiciliares e a organização das documentações das famílias do Programa Bolsa Família apresentaram-se como os métodos mais condizentes eficazes para atingir os objetivos propostos, ou seja, a busca da emancipação dos sujeitos sociais beneficiários do PBF pela regularização de seus cadastros veiculando informações dos direitos de acesso e das condicionalidades para permanência no Programa Bolsa Família.

Trata-se de aprender e ter outro olhar sobre o ambiente e sobre as maneiras de como eles se relacionam ao trabalhar com essas famílias o exercício da cidadania ativa, a horizontalidade nas tomadas de decisão, o trabalho em rede, a coresponsabilidade e a cooperação, entre outros - precisa ser internalizada essa contribuição do profissional assistente social no PBF para que possam permear as atitudes cotidianas dos envolvidos numa co-responsabilidade para a emancipação dos usuários deste programa do Governo Federal. 


\section{Referências bibliográficas}

ANDRADE, Miriam. Manual de Gestão de Benefícios: Programa Bolsa Família. $2^{\underline{a}}$ ed.Brasília: MDS, SENARC: julho/2008. Disponível em: http://www.mds.gov.br/bolsafamilia/menu_superior/manuais-e-publicacoes-1. Acesso em 20/01/2010.

CONSELHO REGIONAL DO SERVIÇO SOCIAL (6" Região). Coletânea de Leis. Belo Horizonte, 2006.

GUEIROS, Dalva Azevedo. Família e proteção social: questões atuais e limites da solidariedade e familiar. Revista Serviço Social \& Sociedade. n.71, set.2002 MDS.

MDS. Caderno informativo sobre o Índice de Gestão Descentralizada do PBF IGD. Disponível em: http://www.mds.gov.br/bolsafamilia/menu_superior/manuais-epublicacoes-1. Acesso em 20/01/2010.

MDS. Programa Bolsa Família. Guia do Gestor. Brasília: Secretaria Nacional de Renda de Cidadania/mds, 2006.

GUEIROS, Dalva Azevedo. Família e proteção social: questões atuais e limites da solidariedade e familiar. Revista Serviço Social \& Sociedade. n.71, set.2002

VITALE, Maria Amália Faller. Famílias monoparentais: indagações. Revista Serviço Social \& Sociedade. n.71, set. 2002

WANDERLEY, Mariângela Belfiore. Refletindo sobre a noção de exclusão. Revista Serviço Social \& Sociedade. n.55. 1997. 